\title{
Effects of gravistimuli on osmoregulation in azuki bean epicotyls
}

\section{Yan Zhang, Kouichi Soga, Kazuyuki Wakabayashi, Takayuki Hoson}

\begin{tabular}{|c|c|}
\hline Citation & Advances in Space Research. 51(3); 458-464 \\
\hline Issue Date & 2013-02-01 \\
\hline Type & Journal Article \\
\hline Textversion & author \\
\hline Rights & $\begin{array}{l}\text { (c) } 2012 \text { Elsevier Ltd. This manuscript version is made available under the } \\
\text { CC-BY-NC-ND } 4.0 \text { License. http://creativecommons.org/licenses/by-nc-nd/4.0/. } \\
\text { This is not the published version. Please cite only the published version. The } \\
\text { article has been published in final form at https://doi.org/10.1016/j.asr.2012.09.013. }\end{array}$ \\
\hline DOI & 10.1016/j.asr.2012.09.013 \\
\hline
\end{tabular}

Self-Archiving by Author(s)

Placed on: Osaka City University 


\title{
Effects of gravistimuli on osmoregulation in azuki bean epicotyls
}

\author{
Yan Zhang, Kouichi Soga, Kazuyuki Wakabayashi, Takayuki Hoson*
}

Department of Biology, Graduate School of Science, Osaka City University, Osaka 558-8585, Japan

* Corresponding author.

E-mail address: hoson@sci.osaka-cu.ac.jp (T. Hoson)

\begin{abstract}
The effects of hypergravity on growth and osmoregulation were examined in dark-grown azuki bean epicotyls. Elongation growth of epicotyls was promptly suppressed by hypergravity at $300 \mathrm{~g}$. On the contrary, the increase in fresh weight of epicotyls during incubation was not suppressed by hypergravity at $300 \mathrm{~g}$ at least up to $6 \mathrm{~h}$. Also, the level of total osmotic solutes increased during epicotyl growth for $6 \mathrm{~h}$, which was not affected by hypergravity. These results suggest that azuki bean epicotyls are capable of maintaining osmoregulation even under $300 \mathrm{~g}$ conditions for a short period. On the other hand, the increase in fresh weight of epicotyls was suppressed, in addition to suppression of elongation growth, when seedlings were treated with $300 \mathrm{~g}$ for $24 \mathrm{~h}$. The increase in level of total osmotic solutes was also inhibited by $24 \mathrm{~h}$ hypergravity treatment, which was accounted by the reduced levels of organic solutes, such as sugars and amino acids. Furthermore, the dry weight of seeds decreased during incubation for $24 \mathrm{~h}$, but the decrease was inhibited by hypergravity at $300 \mathrm{~g}$. Hypergravity treatment at $300 \mathrm{~g}$ for $24 \mathrm{~h}$ also increased the $\mathrm{pH}$ value of apoplastic solution in epicotyls. Taken together, these results suggest that the translocation of organic solutes from the seed to epicotyls is inhibited by prolonged hypergravity treatment, which may underlie the suppression of epicotyl growth, and that the breakdown of $\mathrm{H}^{+}$gradient across the plasma membrane in epicotyl cells may be at least partly involved in the reduction of organic solute accumulation under hypergravity conditions.
\end{abstract}

Keywords: Apoplastic pH; Azuki bean (Vigna angularis); Growth; Hypergravity; Osmoregulation; Translocation 


\section{Introduction}

Plants are subjected to a variety of environmental signals, such as gravity, light, temperature, and water, which strongly influence the processes of plant growth and development. Of these signals, gravity is present permanently on the earth with constant direction and magnitude and serves as the most reliable signal for plants. It is thus essential to clarify the role of gravity in regulating plant growth and development. For this purpose, to change the magnitude of the gravitational force is effective. Unfortunately, true microgravity conditions produced by free fall or parabolic flight are too short for plants to show obvious changes in their growth and development. Therefore, hypergravity conditions produced by centrifugation have provided the only practical and useful experimental systems on earth (Waldron and Brett, 1990; Hoson et al., 1996; Hodick and Sievers, 1998; Fitzelle and Kiss, 2001; Musgrave et al. 2009; Tamaoki et al., 2009). Hypergravity has been shown to suppress elongation growth of shoot organs in various plants (Waldron and Brett, 1990; Hoson et al., 1996; Hoson and Soga, 2003). Hypergravity treatment also decreased the cell wall extensibility, when it suppressed elongation growth of shoot organs (Hoson et al., 1996; Soga et al., 1999a, 1999b, 2001). In addition, hypergravity modified cell wall architecture by altering the metabolic processes of cell wall constituents (Hoson and Soga, 2003; Wakabayashi et al., 2005, 2009). Such cell wall modifications have been considered as a main cause of suppression by hypergravity of shoot growth.

The cellular osmotic properties, as well as the cell wall properties, are important factors regulating the rate of plant cell expansion. It is generally believed that the level of osmotic solutes in plant cells determines the driving force for water uptake, thereby regulating the rate of plant cell growth. Indeed, a positive correlation between osmotic solute content and capacity of cell growth was observed in coleoptiles of dark-grown maize seedlings (Parvez et al., 1996). When white light irradiation suppressed growth of etiolated maize coleoptiles, it decreased the level of osmotic solutes (Parvez et al., 1996, 1998). Also, submergence has been shown to decrease both the level of osmotic solutes and the growth rate of azuki bean epicotyls (Ooume et al., 2009). From these findings, it is hypothesized that modifications to osmoregulation may also be involved in suppression by hypergravity of shoot growth. However, the effects of gravistimuli on the osmotic properties have not been investigated yet.

In the present study, we examined the above hypothesis by analyzing growth and osmotic properties along epicotyls of etiolated azuki bean seedlings grown under hypergravity conditions at $300 \mathrm{~g}$, paying attention to the level of osmotic solutes. Azuki bean is an important crop cultivated widely in East Asia, and whose epicotyls provide a convenient system for investigating growth characteristics in response to environmental stimuli such as gravity, because they show a higher growth rate and a clear growth gradient along epicotyls. We used etiolated seedlings in the present study to avoid the modification by light of gravity effects. Also, hypergravity at $300 \mathrm{~g}$ was employed, because it has been shown by the time course and reversibility analyses that this gravity dose is not an extraordinary stimulus but is within the normal physiological range for plants (Hoson and Soga, 2003). The results obtained indicated that the increase in osmotic solute levels during incubation was maintained for a short period but was inhibited by prolonged hypergravity treatment. Thus, we also examined the mechanism of suppression of osmoregulation by the long-term hypergravity treatment. 


\section{Materials and methods}

\subsection{Plant materials and growth experiments}

Seeds of azuki bean (Vigna angularis Ohwi et Ohashi cv. Erimowase) were soaked in running tap water for $36 \mathrm{~h}$ at $30^{\circ} \mathrm{C}$, and they were then allowed to germinate and grow on gauze spread on a plastic dish filled with water at $25^{\circ} \mathrm{C}$ in the dark. After 5 days, seedlings with an epicotyl with about $55 \mathrm{~mm}$ long were selected. In experiments using whole epicotyls, $50 \mathrm{~mm}$ region $(3-53 \mathrm{~mm}$ below the hook) was marked with India ink. On the other hand, in analyses along epicotyl regions, epicotyls were marked with India ink at 10-mm intervals from the sub-hook region ( $3 \mathrm{~mm}$ below the hook) to the base. The 10-mm regions were designated as the A- to E-regions from the top. The marked seedlings were exposed to basipetal hypergravity at $300 \mathrm{~g}$ with a centrifuge (H-28-F; Kokusan, Japan) for $24 \mathrm{~h}$ in the dark. After incubation, the length of the marked regions was measured using a scale and then excised. The fresh weight of the excised segments was measured with an electronic balance.

For determination of the dry weight, shoots consisting of epicotyls and leaves, and the seed (cotyledons) were excised separately from seedlings that had been grown under $1 g$ or $300 g$ conditions for $24 \mathrm{~h}$, and then dried at $50^{\circ} \mathrm{C}$. The dry weights of shoots and the seed were measured with an electronic balance. All manipulations were done under dim green light.

\subsection{Determination of osmotic properties}

The extraction and collection of cell sap was carried out according to the method of Terry and Bonner (1980) and Ooume et al. (2009). The marked regions excised from epicotyls were immediately frozen with liquid nitrogen and kept at $-80^{\circ} \mathrm{C}$. The cell sap was collected from frozen-thawed segments by centrifugation at $1,400 \mathrm{~g}$ for $10 \mathrm{~min}$ at $4^{\circ} \mathrm{C}$. The osmotic concentration of the collected cell sap was measured with a vapour pressure osmometer (Model $5500 \mathrm{C}$, Wescor, Logan, UT, USA). The amount of total osmotic solutes in the epicotyl regions was estimated as the product of the osmotic concentration and the fresh weight. The content of sugars in the cell sap was determined by the phenol-sulfuric acid method (Dubios et al., 1956) and expressed as glucose equivalents, and that of amino acids by the ninhydrin method (Moore and Stein, 1954) as leucine equivalents. The amount of potassium ions was determined with an ion meter (C-131, Horiba, Kyoto, Japan).

\subsection{Measurement of apoplastic $p H$}

The $\mathrm{pH}$ of the apoplastic solution was measured by the method of Soga et al. (2000). The excised regions of azuki bean epicotyls were rinsed with water and placed in parallel on a stainless mesh in the barrel of a plastic syringe. After removal of excess water on the surface of the segments by flash centrifugation, the segments were centrifuged in the longitudinal direction at 1,500 $g$ for 20 min at $4^{\circ} \mathrm{C}$ to collect the apoplastic solution. The $\mathrm{pH}$ of the apoplastic solution was measured immediately after the centrifugation with a $\mathrm{pH}$ meter (B-212, Horiba, Kyoto, Japan) equipped with a flat-surface electrode. 


\subsection{Determination of ATP content}

ATP was determined according to method of Wulff and Doppen (1985) and Jaworek and Welshch (1985). Briefly, ATP was extracted from frozen tissue powder with ice-cold $10 \%$ perchloric acid (v/v) with 5mM EDTA. The extract was centrifuged at $18,500 \mathrm{~g}$ for $10 \mathrm{~min}$ at $4^{\circ} \mathrm{C}$ and the supernatant was collected. Next, $3 \mathrm{M} \mathrm{KOH}$ was added to the supernatant to adjust the $\mathrm{pH}$ to 7-8. After the $\mathrm{pH}$ adjustment, the solution was centrifuged at $18,500 \mathrm{~g}$ for $10 \mathrm{~min}$ at $4{ }^{\circ} \mathrm{C}$, and the supernatant was immediately used for the ATP measurement. The supernatant was mixed with the test solution containing $500 \mathrm{mM}$ HEPES buffer, $900 \mathrm{mM} \mathrm{MgCl} 2,180 \mathrm{mM}$ glucose, $9.9 \mathrm{mM}$ NADP and $1.4 \mathrm{U} \mathrm{ml}^{-1}$ glucose-6-phosphate dehydrogenase (EC 1.1.1.49, Oriental Yeast, Japan) and incubated for $10 \mathrm{~min}$ at $25^{\circ} \mathrm{C}$. After the measurement of absorbance at $340 \mathrm{~nm}, 2 \mathrm{U} \mathrm{ml}^{-1}$ hexokinase (EC 2.7.1.1, Oriental Yeast, Japan) was added to the mixture solution. The mixture solution was further incubated for $10 \mathrm{~min}$ at $25^{\circ} \mathrm{C}$, and absorbance at $340 \mathrm{~nm}$ was measured. ATP content was determined by measuring the difference of absorbance at $340 \mathrm{~nm}$ before and after the addition of hexokinase.

\subsection{Statistical analysis}

For each measurement, the means and the standard errors of the means (SE) were calculated. The significance of differences between control $(1 \mathrm{~g})$ and hypergravity $(300 \mathrm{~g})$ treatments was analyzed by the Student's paired t-test.

\section{Results}

\subsection{Epicotyl growth}

We first investigated the time course changes in the length and the fresh weight of whole epicotyls grown under $1 \mathrm{~g}$ and $300 \mathrm{~g}$ conditions. Hypergravity treatment promptly suppressed elongation growth of epicotyls (Fig. 1A), as reported (Soga et al., 2003, 2006). On the contrary, the increase in fresh weight of epicotyls during incubation was not suppressed by hypergravity at $300 \mathrm{~g}$ up to $6 \mathrm{~h}$. At $12 \mathrm{~h}$ and after, hypergravity at $300 \mathrm{~g}$ suppressed the increase in fresh weight of whole epicotyls, in addition to suppression of elongation growth (Fig. 1B). Based on such results, we selected $6 \mathrm{~h}$ and $24 \mathrm{~h}$ as target time points and measured growth and osmotic properties of various regions along epicotyls, to clarify the effect of hypergravity on osmoregulation. In control epicotyls, the length and the fresh weight increased substantially in A-region and slightly in B-region, but not in lower ( $\mathrm{C}$ to $\mathrm{E}$ ) regions during incubation up to $24 \mathrm{~h}$ (Figs. 2 and 3). Namely, epicotyl growth occurred mostly in the upper A-region. Hypergravity treatment for $6 \mathrm{~h}$ significantly suppressed elongation growth (Fig. 2), whereas it did not affect the increase in fresh weight in A-region (Fig. 3). The value of fresh weight per unit length of A-region, which represents the thickness of region, was higher in hypergravity-treated epicotyls $(3.6 \mathrm{mg} / \mathrm{mm})$ than in the control $(3.3 \mathrm{mg} / \mathrm{mm})$. These results indicate that hypergravity treatment promptly suppressed elongation growth and stimulated lateral expansion in the growing regions of epicotyls. On the other hand, hypergravity treatment for $24 \mathrm{~h}$ substantially decreased the fresh weight of A- and B-regions (Fig. 3), in addition to suppression of 
elongation growth (Fig. 2). Thus, the action pattern of hypergravity on growth is clearly different between the short term and long term treatments.

\subsection{Osmotic properties}

The level of total osmotic solutes increased substantially in A-region and slightly in B-region during incubation, but not in the lower regions (Fig. 4). The increase in total osmotic solutes in A-region was not clearly affected by hypergravity treatment for $6 \mathrm{~h}$, whereas the increase was substantially inhibited by $24 \mathrm{~h}$ treatment.

In azuki bean epicotyls, osmotic solutes consisted mainly of sugars and amino acids, with lesser amounts of potassium ions (Ooume et al., 2009). We examined the effects of hypergravity on the levels of these osmotic solutes in various regions along epicotyls (Fig. 5). The levels of all solutes increased substantially in A-region and slightly in B-region during incubation, whereas those in the lower regions barely changed. The levels of sugars, amino acids, or potassium ions in A-region were not influenced by $6 \mathrm{~h}$ hypergravity treatment. On the other hand, hypergravity treatment for $24 \mathrm{~h}$ substantially decreased the levels of organic substances, sugars and amino acids, but not the levels of potassium ions in A-region.

\subsection{Dry weight of shoots and the seed}

We measured the changes in dry weights of shoots and the seed separately, to determine whether prolonged hypergravity affects the translocation of osmotic solutes. During incubation for $24 \mathrm{~h}$, the dry weight of shoots increased, whereas that of the seed decreased (Fig. 6). Hypergravity treatment significantly inhibited both the increase in dry weight of shoots and the decrease in that of the seed.

\subsection{Apoplastic $p H$ and level of ATP}

We measured the $\mathrm{pH}$ of apoplastic solution and the level of cellular ATP in A-region of epicotyls, to clarify the mechanism by which hypergravity decreases the levels of organic solutes. The $\mathrm{pH}$ value of apoplastic solution in A-region of control epicotyls gradually increased during incubation (Fig. 7). Hypergravity treatment for $6 \mathrm{~h}$ did not affect the $\mathrm{pH}$ value, whereas that for $24 \mathrm{~h}$ significantly increased the value.

ATP content per region increased during $6 \mathrm{~h}$ incubation, and that per the fresh weight was constant for $6 \mathrm{~h}$ and then decreased to about $40 \%$ of the initial level after $24 \mathrm{~h}$ (Table 1). Hypergravity did not significantly affect the levels of ATP in A-region, irrespective of incubation period or basis of levels.

\section{Discussion}

When azuki bean seedlings were treated with hypergravity at $300 \mathrm{~g}$ for $6 \mathrm{~h}$ in the dark, elongation growth of epicotyls was significantly suppressed (Figs. 1 and 2), whereas the increase in their fresh weight during incubation was not clearly influenced (Figs. 1 and 3). The level of total 
osmotic solutes increased during epicotyl growth for $6 \mathrm{~h}$, which was also not affected by hypergravity (Fig. 4). These results suggest that azuki bean epicotyls are capable of maintaining osmoregulation even under $300 \mathrm{~g}$ conditions for a short period. It is generally believed that plant cell enlargement is initiated by relaxation of the cell wall, followed by water uptake in response to reduced cellular water potential (Cosgrove, 2005). Thus, the decrease in the mechanical extensibility of cell walls (Soga et al., 1999b) may be a main cause of suppression by hypergravity of short-term elongation growth. Hypergravity at $300 \mathrm{~g}$ for $6 \mathrm{~h}$ not only suppressed elongation growth but stimulated lateral expansion, namely modified growth anisotropy, which may be caused by reorientation of cortical microtubules from transverse to longitudinal directions (Soga et al., 2006, 2008). Involvement of cortical microtubules in hypergravity-induced growth modifications has been supported by analysis with microtubule-disrupting reagents and tubulin mutants (Matsumoto et al., 2007, 2010; Hoson et al., 2010).

When azuki bean seedlings were treated with hypergravity at $300 \mathrm{~g}$ for $24 \mathrm{~h}$, the increase in fresh weight of epicotyls was suppressed (Figs. 1B and 3), in addition to suppression of elongation growth (Figs. 1A and 2). Growth suppression by prolonged hypergravity treatment is thus not merely a modification to growth anisotropy, but that accompanying a decrease in net volume of epicotyls. The increase in level of total osmotic solutes was also inhibited by $24 \mathrm{~h}$ hypergravity treatment (Fig. 4). The result suggests that the inhibition of osmoregulation overlays and strengthens growth suppression due to a decrease in the cell wall extensibility in prolonged hypergravity treatment.

The inhibition by $24 \mathrm{~h}$ hypergravity treatment of an increase in level of total osmotic solutes was accounted by the reduced levels of organic solutes, such as sugars and amino acids (Fig. 5). The seed is the sole source of assimilates for etiolated seedlings and thus the translocation processes of organic compounds from the seed to epicotyls may be inhibited by prolonged hypergravity. Actually, the decrease in dry weight of seeds during incubation was inhibited by hypergravity, in accordance with an inhibition of an increase in shoot dry weight (Fig. 6). Hypergravity treatment for $24 \mathrm{~h}$ also increased the $\mathrm{pH}$ value of apoplastic solution in epicotyls (Fig. 7). Organic compounds translocated from the seed are taken up by sink cells with the aid of hydrogen ion gradient across the plasma membrane that is produced by the action of proton pumps (Bush, 1993). These results suggest that the translocation of organic solutes from the seed to epicotyls is inhibited by prolonged hypergravity treatment, which may underlie the suppression of epicotyl growth. Also, the breakdown of $\mathrm{H}^{+}$ gradient across the plasma membrane in epicotyl cells may be at least partly involved in the reduction of organic solute accumulation under hypergravity conditions.

Complete submergence severely reduces the growth rate of shoot organs. It has been reported that a decrease in the levels of osmotic solutes is a main cause of underwater growth suppression in azuki bean epicotyls, which may be brought about by suppression of solute uptake via breakdown of $\mathrm{H}^{+}$gradient across the plasma membrane due to a decrease in the level of ATP (Ooume et al., 2009). On the other hand, hypergravity at $300 \mathrm{~g}$ for $24 \mathrm{~h}$ did not significantly affect the levels of ATP in azuki bean epicotyls (Table 1). What is the mechanism by which hypergravity increases the $\mathrm{pH}$ value of apoplastic solution in epicotyls? Because hypergravity had no effects on growth or the mechanical properties of the cell wall of shoot organs in the presence of blockers of mechanosensitive ion channels (mechanoreceptors), lanthanum and gadolinium ions, such receptors on the plasma membrane may be involved in the perception of gravity signal in hypergravity-induced growth modifications (Soga et al., 2004, 2005). Also, hypergravity induced changes in membrane lipid composition (Koizumi et al., 2007), which may modify the activity of proton pumps (Kasamo, 2003). 
In addition, it has been suggested that membrane sterols form the raft structure and thereby act in signal transformation and transduction of gravity signal (Hoson et al., 2005, 2009). Gravity signal perceived by mechanoreceptors may thus directly, or via membrane lipid constituents, modify the activity of proton pumps, thereby increasing the apoplastic $\mathrm{pH}$. We need to examine this possibility by further study.

The present study shows that azuki bean epicotyls are capable of maintaining osmoregulation even under $300 \mathrm{~g}$ conditions at least for a short period (Fig. 4). Also, azuki epicotyls keep the levels of ATP under hypergravity at $300 \mathrm{~g}$ for $24 \mathrm{~h}$ (Table 1). Such high capacity of osmoregulation in seedlings may greatly contribute to gravity resistance, mechanical resistance of plants to the gravitational force (Hoson and Soga, 2003; Hoson et al., 2005). The cell wall plays a central role in gravity resistance, and suitable cooperation between the cell wall and osmotic properties is needed to maintain the mechanical strength of plant body. The reduced growth rate of shoot organs by hypergravity at $300 \mathrm{~g}$ recovered promptly when they were transferred back to $1 \mathrm{~g}$ (Soga et al. 2003). Osmoregulation may be important for such reversibility of plant responses to hypergravity. The present results also support the view that hypergravity at $300 \mathrm{~g}$ is not an extraordinary stimulus but is within the normal physiological range for plants (Hoson and Soga, 2003).

Under microgravity conditions in space, elongation growth of rice coleoptiles and Arabidopsis hypocotyls was stimulated (Hoson et al., 2002; Soga et al., 2002). The cell wall extensibility was also higher in space-grown coleoptiles and hypocotyls than in the controls. Furthermore, the changes in the chemical nature of the cell wall constituents in both organs in space are just opposite to those induced by hypergravity (Hoson and Soga, 2003; Hoson et al., 2005). Such metabolic changes in the cell wall constituents may lead to an increase in the cell wall extensibility, thereby stimulating elongation growth in space. So far, no information has been obtained for modifications to osmoregulation under microgravity conditions. We need to examine the possible involvement of osmoregulation in growth regulation under microgravity conditions by future space experiments.

\section{Acknowledgements}

The present study was supported in part by a grant from the Japan Aerospace Exploration Agency.

\section{References}

Bush, D.R. Proton-coupled sugar and amino acid transporters in plants. Annu. Rev. Plant Physiol. Plant Mol. Biol. 44, 513-541, 1993.

Cosgrove, D.J. Growth of the plant cell wall. Nat. Rev. Mol. Cell Biol. 6, 850-861, 2005.

Dobios, M., Gillers, K.A., Hamilton, J.K., et al. Colorimetric method for determination of sugars and related substances. Anal. Chem. 28, 350-356, 1965.

Fitzelle, K.J., Kiss, J.Z. Restoration of gravitropic sensitivity in starch-deficient mutants of Arabidopsis by hypergravity. J. Exp. Bot. 52, 265-275, 2001. 
Hodick, D., Sievers, A. Hypergravity can reduce but not enhance the gravitropic response of Chara globularis protonemata. Protoplasm 204, 145-154, 1998.

Hoson T., Soga K. New aspects of gravity responses in plant cells. Int. Rev. Cytol. 229, 209-244, 2003.

Hoson, T., Soga, K., Wakabayashi, K. Role of the cell wall-sustaining system in gravity resistance in plants. Biol. Sci. Space 23, 131-136, 2009.

Hoson, T., Matsumoto, S., Soga, K. et al. Cortical microtubules are responsible for gravity resistance in plants. Plant Signal. Behav. 5, 752-754, 2010.

Hoson, T., Nishitani, K., Miyamoto, K., et al. Effects of hypergravity on growth and cell wall properties of cress hypocotyls. J. Exp. Bot. 47, 513-517, 1996.

Hoson, T., Saito, Y., Soga, K., et al. Signal perception, transduction, and response in gravity resistance. Another graviresponse in plants. Adv. Space Res. 36, 1196-1202, 2005.

Hoson, T., Soga, K., Mori, R. et al. Stimulation of elongation growth and cell wall loosening in rice coleoptiles under microgravity conditions in space. Plant Cell Physiol. 43, 1067-1071, 2002.

Jaworek, D., Welsch, J. Adenosine 5'-diphosphate and adenosine 5'-monophosphate, in: Bergmeyer, H.U., Bergmeyer, J., Graß, M. (Eds.), Methods of enzymatic analysis, Vol. 7. Weinheim, Germany, pp. 365-370, 1985.

Kasamo, K. Regulation of plasma membrane $\mathrm{H}^{+}$-ATPase activity by the membrane environment. J. Plant Res. 116, 517-523, 2003.

Koizumi, T., Sakaki, T., Usui, S., et al. Changes in membrane lipid composition in azuki bean epicotyls under hypergravity conditions: Possible role of membrane sterols in gravity resistance. Adv. Space Res. 39, 1198-1203, 2007.

Matsumoto, S., Kumasaki, S., Soga, K., et al. Gravity- induced modifications to development in hypocotyls of Arabidopsis tubulin mutants. Plant Physiol. 152, 918-926, 2010.

Matsumoto, S., Saito, Y., Kumasaki, S., et al. Up-regulation of tubulin genes and roles of microtubules in hypergravity-induced growth modifications in Arabidopsis hypocotyls. Adv. Space Res. 39, 1176-1181, 2007.

Moore, S., Stein, W.H. A modified ninhydrin reagent for the photometric determination of amino acids and related compounds. J. Biol. Chem. 211, 907-913, 1954.

Musgrave, M.E., Kuang, A., Allen, J., et al. Hypergravity prevents seed production in Arabidopsis by disrupting pollen tube growth. Planta, 230, 863-870, 2009. 
Ooume, K., Inoue, Y., Soga, K., et al. Cellular basis of growth suppression by submergence in azuki bean epicotyls. Ann. Bot. 103, 325-332, 2009.

Parvez, M.M., Wakabayashi, K., Hoson, T., et al. Changes in cellular osmotic potential and mechanical properties of cell walls during light-induced inhibition of cell elongation in maize coleoptiles. Physiol. Plant. 96, 179-185, 1996.

Parvez, M.M., Wakabayashi, K., Hoson, T., et al. White light-induced sugar distribution controls growth and osmotic properties in the coleoptile and the first leaf in Zea mays seedlings. Physiol. Plant. 102, 1-8, 1998.

Soga, K., Harada, K., Wakabayashi, K., et al. Increased molecular mass of hemicellulosic polysaccharides is involved in growth inhibition of maize coleoptiles and mesocotyls under hypergravity conditions. J. Plant Res. 112, 273-278, 1999a.

Soga, K., Kotake, T., Wakabayashi, K., et al. Transient increase in the transcript levels of $\gamma$-tubulin complex genes during reorientation of cortical microtubules by gravity in azuki bean (Vigna angularis) epicotyls, J. Plant Res. 121, 493-498, 2008.

Soga, K., Wakabayashi, K., Hoson, T., et al. Hypergravity increases the molecular size of xyloglucans by decreasing xyloglucan-degrading activity in azuki bean epicotyls. Plant Cell Physiol. 40, 581-585, $1999 \mathrm{~b}$.

Soga, K., Wakabayashi, K., Hoson, T., et al. Changes in the apoplastic pH are involved in regulation of xyloglucan breakdown of azuki bean epicotyls under hypergravity conditions. Plant Cell Physiol. 41, 509-514, 2000.

Soga, K., Wakabayashi, K., Hoson, T., et al. Gravitational force regulates elongation growth of Arabidopsis hypocotyls by modifying xyloglucan metabolism. Adv. Space Res. 27, 1011-1016, 2001.

Soga, K., Wakabayashi, K., Kamisaka, S. et al. Stimulation of elongation growth and xyloglucan breakdown in Arabidopsis hypocotyls under microgravity conditions in space. Planta 215, 1040-1046, 2002.

Soga, K., Wakabayashi, K., Kamisaka, S. et al. Growth restoration in azuki bean and maize seedlings by removal of hypergravity stimuli. Adv. Space Res. 31, 2269-2274, 2003.

Soga, K., Wakabayashi, K., Kamisaka, S. et al. Graviperception in growth inhibition of plant shoots under hypergravity conditions produced by centrifugation is independent of that in gravitropism and may involve mechanoreceptors. Planta 218, 1054-1061, 2004.

Soga, K., Wakabayashi, K., Kamisaka, S. et al. Mechanoreceptors rather than sedimentable 
amyloplasts perceive the gravity signal in hypergravity-induced inhibition of root growth in azuki bean. Funct. Plant Biol. 32, 175-179, 2005.

Soga, K., Wakabayashi, K., Kamisaka, S., et al. Hypergravity induces reorientation of cortical microtubules and modifies growth anisotropy in azuki bean epicotyls. Planta 224, 1485-1494, 2006.

Tamaoki, D., Karahara, I., Nishiuchi, T., et al. Transcriptome profiling in Arabidopsis inflorescence stems grown under hypergravity in terms of cell walls and plant hormones. Adv. Space Res. 44, 245-253, 2009.

Terry, M.E., Bonner, B.A. An examination of centrifugation as a method of extracting an extracellular solution from peas, and its use for the study of indoleacetic acid-induced growth. Plant Physiol. 66, 321-325, 1980.

Wakabayashi, K., Soga, K., Kamisaka, S., et al. Increase in the level of arabinoxylan-hydroxycinnamate network in cell walls of wheat coleoptiles grown under continuous hypergravity conditions. Physiol. Plant. 125, 127-134, 2005.

Wakabayashi, K., Soga, K., Hoson T. Modification of cell wall architecture in gramineous plants under altered gravity conditions. Biol. Sci. Space 23, 137-142, 2009.

Waldron, K.W., Brett, C.T. Effects of extreme acceleration on the germination, growth and cell wall composition of pea epicotyls. J. Exp. Bot. 41, 71-77, 1990.

Wulff, K., Doppen, W. ATP: luminometric method, in: Bergmeyer, H. U., Bergmeyer, J., Graß, M., (Eds.), Methods of enzymatic analysis, Vol. 7. Weinheim, Germany, pp. 357-364, 1985. 
Figure legends

Fig. 1.

Effects of hypergravity on the length (A) and the fresh weight (B) of whole azuki bean epicotyls. Seedlings that had a $55 \mathrm{~mm}$ long epicotyl were selected, and $50 \mathrm{~mm}$ region $(3-53 \mathrm{~mm}$ below the hook) was marked. The marked seedlings were grown under $1 \mathrm{~g}$ and $300 \mathrm{~g}$ conditions in the dark. After the incubation, the length and the fresh weight of marked region were measured. Data are mean $\pm \mathrm{SE}(\mathrm{n}=10)$. *, Mean values with significant differences between $1 \mathrm{~g}$ and $300 \mathrm{~g}$ treatments $(\mathrm{P}<0.05)$. Error bars were smaller than the symbols for some points.

Fig. 1.

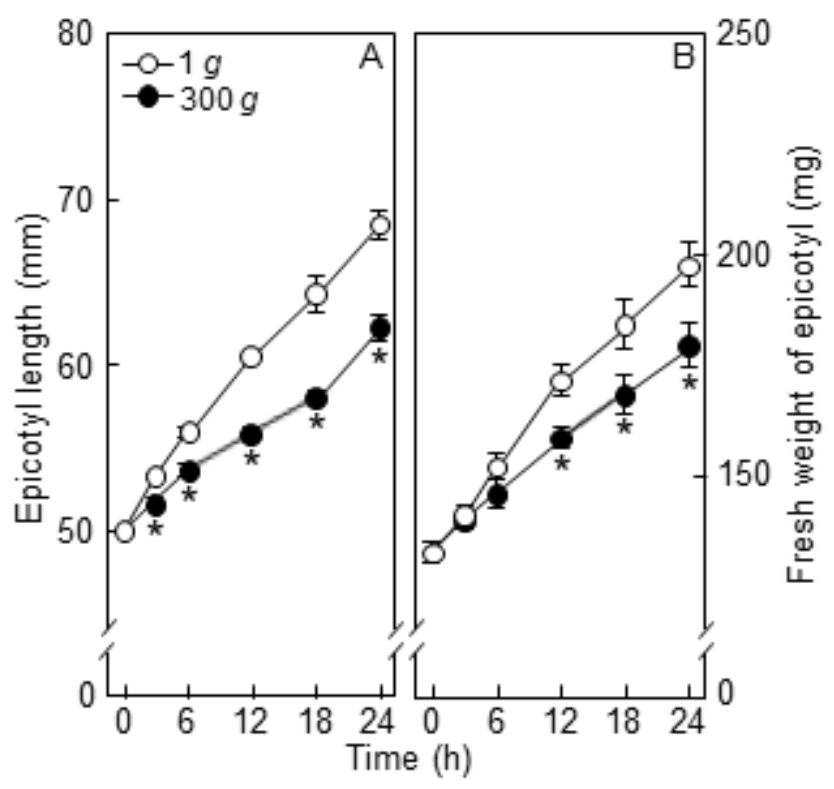


Fig. 2.

Effects of hypergravity on elongation growth in various regions along azuki bean epicotyls. Seedlings that had a $55 \mathrm{~mm}$ long epicotyl were selected, and epicotyls were marked at 10-mm interval from the region $3 \mathrm{~mm}$ below the hook. The $10-\mathrm{mm}$ regions were designated as A- to E-regions from the top. The marked seedlings were grown at $1 \mathrm{~g}$ or $300 \mathrm{~g}$ conditions for $6 \mathrm{~h}$ and $24 \mathrm{~h}$ in the dark. After the incubation, the length of each region was measured. Data are means $\pm \mathrm{SE}(\mathrm{n}=$ 20). *, Mean values with significant differences between $1 \mathrm{~g}$ and $300 \mathrm{~g}$ treatments $(\mathrm{P}<0.05)$.

Fig. 2.

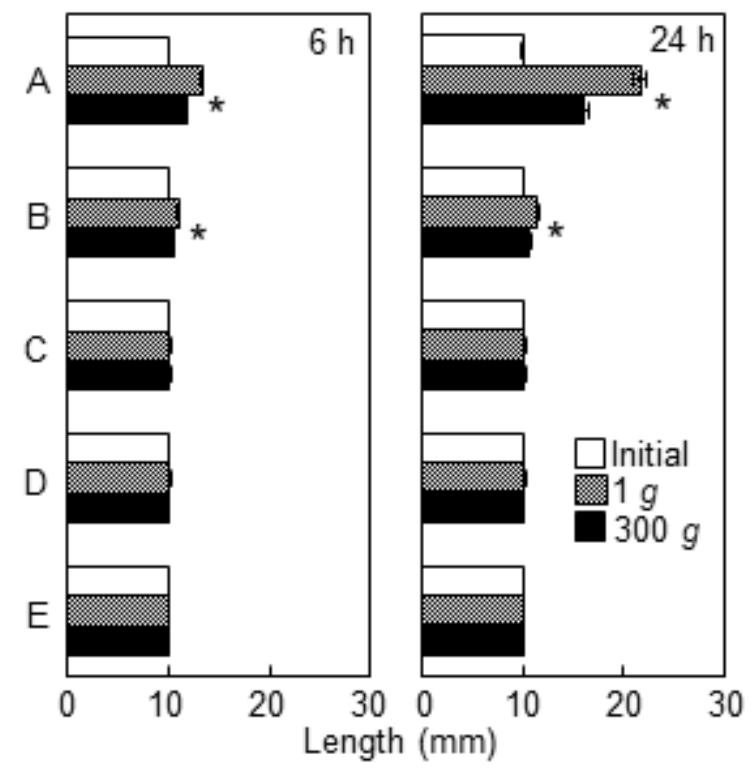


Fig. 3.

Effects of hypergravity on the fresh weight in various regions along azuki bean epicotyls. Growth conditions are as shown in Fig. 2. After the measurement of length of each region, marked regions were excised, and then the fresh weight was measured. Data are means $\pm \operatorname{SE}(n=5)$. *, Mean $^{*}$ values with significant differences between $1 g$ and $300 g$ treatments $(\mathrm{P}<0.05)$.

Fig. 3.

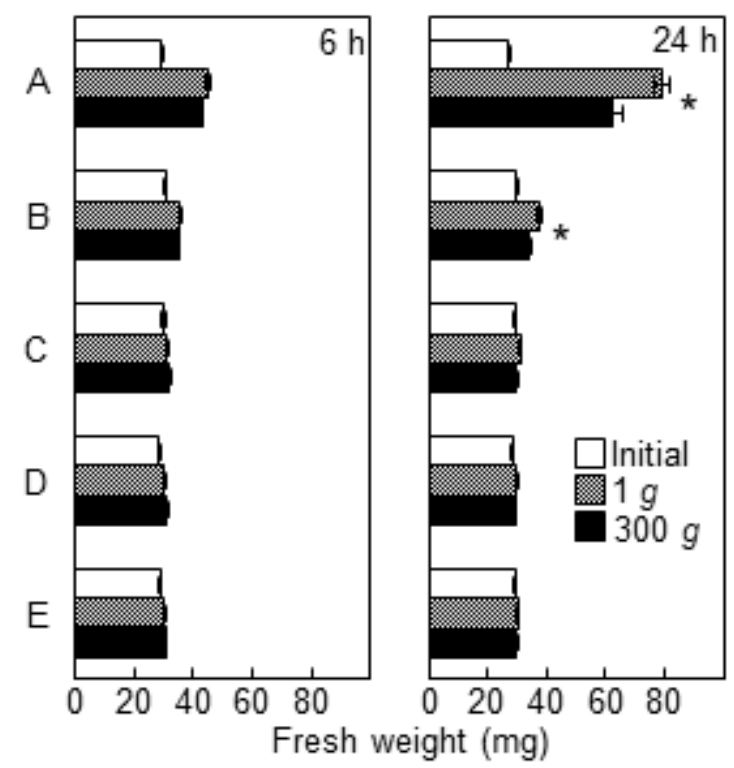


Fig. 4.

Effects of hypergravity on osmotic solute contents in various regions along azuki bean epicotyls. Growth conditions are as shown in Fig. 2. The analytical procedures are as shown in Materials and Methods. Data are means \pm SE $(n=4)$. *, Mean values with significant differences between $1 \mathrm{~g}$ and $300 \mathrm{~g}$ treatments $(\mathrm{P}<0.05)$.

Fig. 4 .

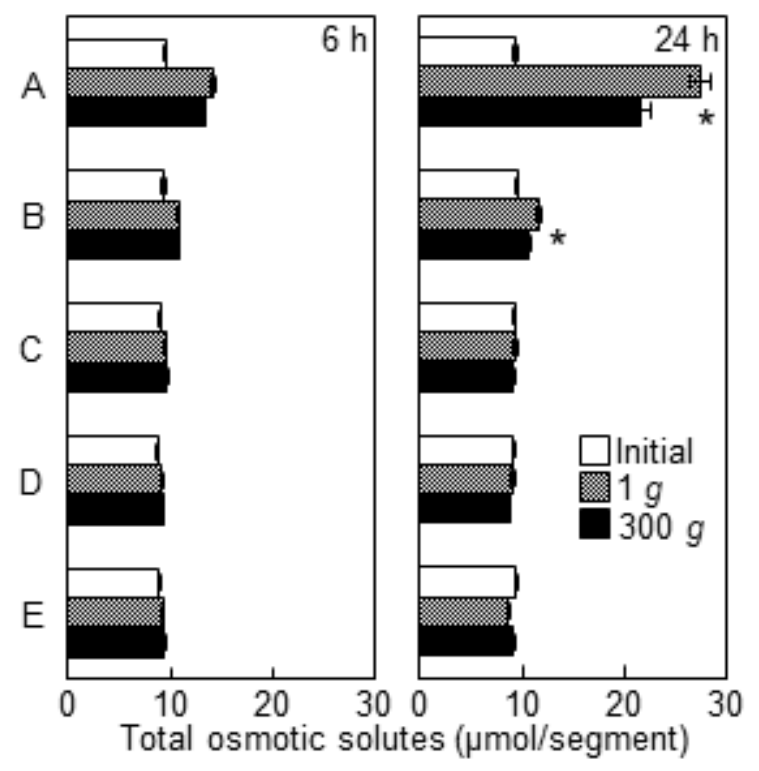


Fig. 5.

Effects of hypergravity on contents of major osmotic solutes in various regions along azuki bean epicotyls. Growth conditions are as shown in Fig. 2. The analytical procedures are as shown in Materials and Methods. Data are means \pm SE $(n=4)$. *, Mean values with significant differences between $1 g$ and $300 g$ treatments $(\mathrm{P}<0.05)$.

Fig. 5 ,

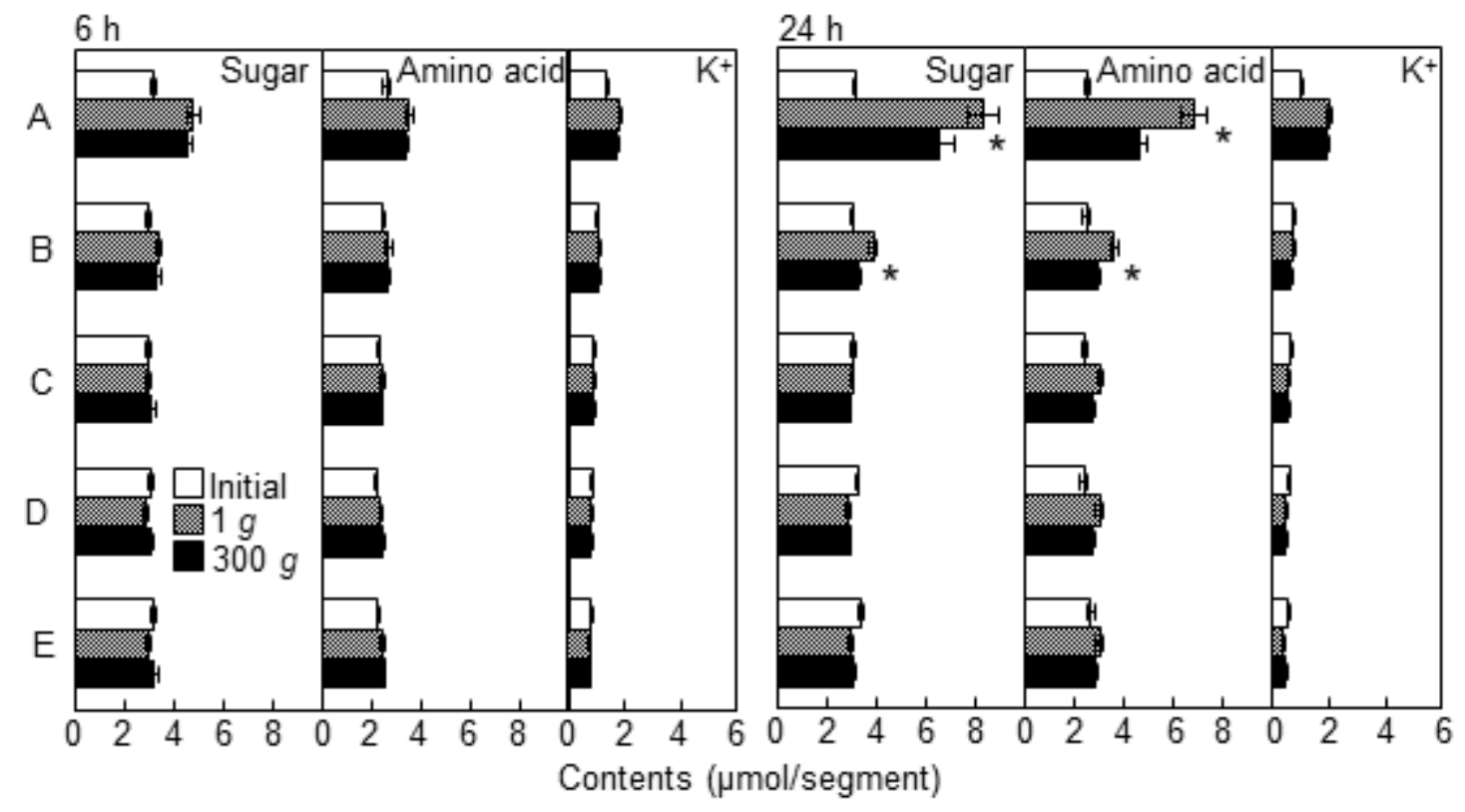


Fig. 6.

Effects of hypergravity on the dry weights of shoots (A) and the seed (B) of azuki bean seedlings. Seedlings that had a $55 \mathrm{~mm}$ long epicotyl were grown at $1 \mathrm{~g}$ or $300 \mathrm{~g}$ conditions for $24 \mathrm{~h}$ in the dark. After incubation, shoots, consisting of epicotyls and leaves, and the seed were excised separately from seedlings. Excised shoots and seed were dried and their dry weights were measured. Data are means \pm SE $(n=20)$. *, Mean values with significant differences between $1 \mathrm{~g}$ and $300 \mathrm{~g}$ treatments $(\mathrm{P}<0.05)$.

Fig. 6 .

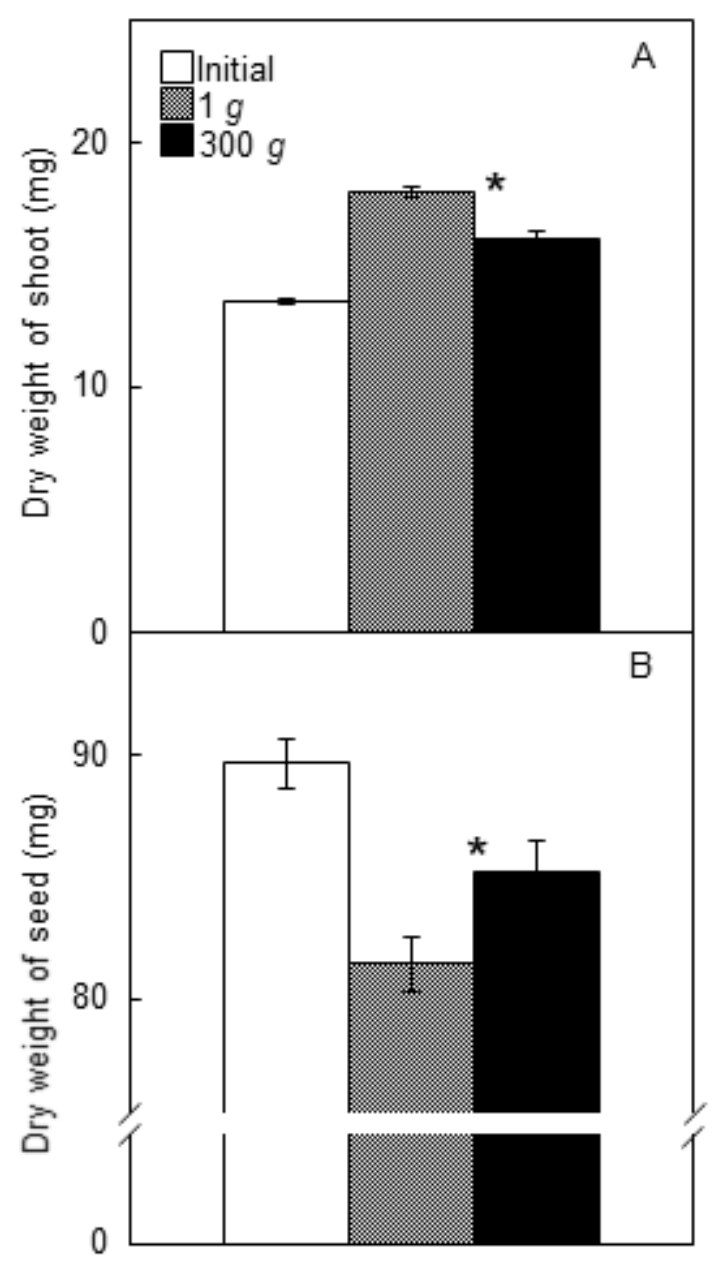


Fig. 7.

Effects of hypergravity on apoplastic $\mathrm{pH}$ in A-region of azuki bean epicotyls. Growth conditions are as shown in Fig. 2. The apoplastic solution was obtained from excised regions, and the $\mathrm{pH}$ value of the solution was measured as described in Materials and Methods. Data are means $\pm \operatorname{SE}(\mathrm{n}=4)$. *, Mean values with significant differences between $1 g$ and $300 g$ treatments $(\mathrm{P}<0.05)$.

Fig. 7.

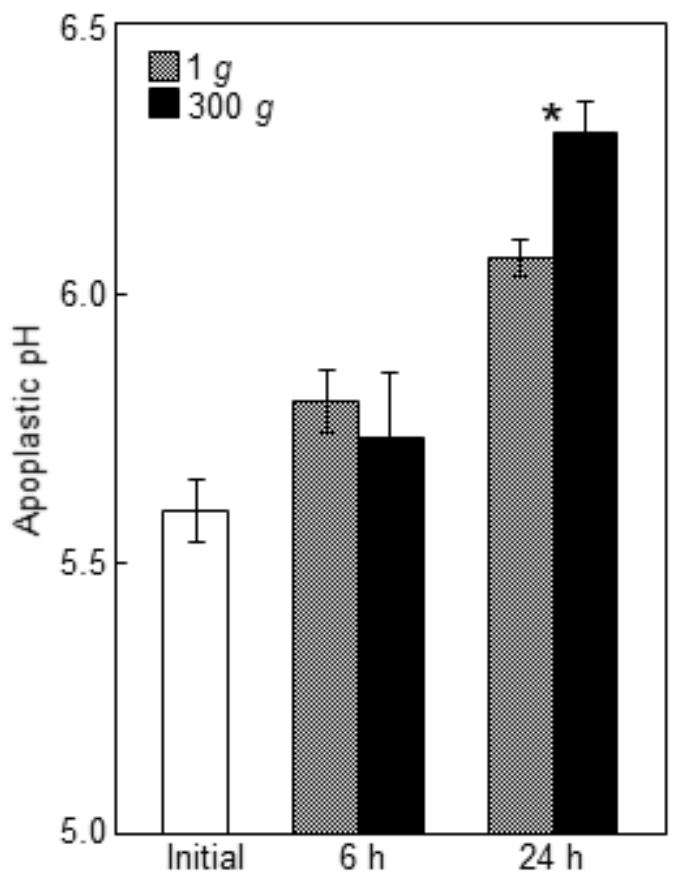


Table 1

Effects of hypergravity on ATP content in A-region of azuki bean epicotyls.

\begin{tabular}{lll}
\hline & \multicolumn{2}{l}{ ATP content } \\
\cline { 2 - 3 } & nmol/segment & nmol/g fresh weight \\
\hline Initial & $10.3 \pm 0.85$ & $414.0 \pm 35.7$ \\
$6 \mathrm{~h}, 1 \mathrm{~g}$ & $16.7 \pm 1.47$ & $372.7 \pm 34.9$ \\
$6 \mathrm{~h}, 300 \mathrm{~g}$ & $15.6 \pm 2.97$ & $402.4 \pm 73.9$ \\
$24 \mathrm{~h}, 1 \mathrm{~g}$ & $14.7 \pm 1.27$ & $149.0 \pm 12.8$ \\
$24 \mathrm{~h}, 300 \mathrm{~g}$ & $12.7 \pm 0.84$ & $187.2 \pm 18.5$ \\
\hline
\end{tabular}

Growth conditions are as shown in Fig. 2. ATP content in A-region was determined. The analytical procedures are as shown in Materials and Methods. Data are means \pm SE $(n=4)$. No significant differences between $1 \mathrm{~g}$ and $300 \mathrm{~g}$ treatments were detected in any incubation period or basis of ATP content. 